\title{
An assessment of frailty as a tool for risk stratification in adult spinal deformity surgery
}

\author{
Emily K. Miller, MD, ${ }^{1}$ Brian J. Neuman, MD, ${ }^{1}$ Amit Jain, MD, ${ }^{1}$ Alan H. Daniels, MD, ${ }^{2}$ \\ Tamir Ailon, MD, MPH, ${ }^{3}$ Daniel M. Sciubba, MD, ${ }^{4}$ Khaled M. Kebaish, MD, ${ }^{1}$ Virginie Lafage, PhD, ${ }^{5}$ \\ Justin K. Scheer, MD, ${ }^{6}$ Justin S. Smith, MD, PhD, ${ }^{7}$ Shay Bess, MD, ${ }^{8}$ Christopher I. Shaffrey, MD, ${ }^{7}$ \\ Christopher P. Ames, MD, ${ }^{9}$ and the International Spine Study Group
}

Departments of ${ }^{1}$ Orthopaedic Surgery and ${ }^{4}$ Neurosurgery, The Johns Hopkins University, Baltimore, Maryland; ${ }^{2}$ Department of Orthopaedic Surgery, The Alpert Medical School of Brown University, Providence, Rhode Island; ${ }^{3}$ Department of Orthopaedics, University of British Columbia, Vancouver, British Columbia, Canada; ${ }^{5}$ Department of Orthopaedic Surgery, Hospital for Special Surgery, New York, New York; ${ }^{6}$ University of California San Diego School of Medicine, San Diego, California; ${ }^{7}$ Department of Neurosurgery, University of Virginia Health System, Charlottesville, Virginia; ${ }^{8}$ Denver International Spine Center, Presbyterian St. Luke's/Rocky Mountain Hospital for Children, Denver, Colorado; and 'Department of Neurosurgery, University of California San Francisco School of Medicine, San Francisco, California

OBJECTIVE The goal of this study was to analyze the value of an adult spinal deformity frailty index (ASD-FI) in preoperative risk stratification. Preoperative risk assessment is imperative before procedures known to have high complication rates, such as ASD surgery. Frailty has been associated with risk of complications in trauma surgery, and preoperative frailty assessments could improve the accuracy of risk stratification by providing a comprehensive analysis of patient factors that contribute to an increased risk of complications.

METHODS Using 40 variables, the authors calculated frailty scores with a validated method for 417 patients (enrolled between 2010 and 2014) with a minimum 2-year follow-up in an ASD database. On the basis of these scores, the authors categorized patients as not frail (NF) $(<0.3$ points), frail ( $0.3-0.5$ points), or severely frail (SF) $(>0.5$ points). The correlation between frailty category and incidence of complications was analyzed.

RESULTS The overall mean ASD-FI score was 0.33 (range 0.0-0.8). Compared with NF patients ( $n=183$ ), frail patients $(n=158)$ and SF patients $(n=109)$ had longer mean hospital stays (1.2 and 1.6 times longer, respectively; $p<$ 0.001). The adjusted odds of experiencing a major intraoperative or postoperative complication were higher for frail patients (OR 2.8) and SF patients ( 4.1) compared with NF patients $(p<0.01)$. For frail and SF patients, respectively, the adjusted odds of developing proximal junctional kyphosis (OR 2.8 and 3.1) were higher than those for NF patients. The SF patients had higher odds of developing pseudarthrosis (OR 13.0), deep wound infection (OR 8.0), and wound dehiscence (OR 13.4) than NF patients $(p<0.05)$, and they had 2.1 times greater odds of reoperation $(p<0.05)$.

CONCLUSIONS Greater patient frailty, as measured by the ASD-FI, was associated with worse outcome in many common quality and value metrics, including greater risk of major complications, proximal junctional kyphosis, pseudarthrosis, deep wound infection, wound dehiscence, reoperation, and longer hospital stay.

https://thejns.org/doi/abs/10.3171/2017.10.FOCUS17472

KEY WORDS adult spinal deformity; complications; frailty index; personalized preoperative risk stratification

$\mathrm{F}$ RAILTY is a relatively new medical diagnosis with many contributors that is characterized by reduced physiological function or increased physiological age, which increases an individual's vulnerability to injury. Health tends to deteriorate at different rates for differ- ent people, leading to a discrepancy between physiological age and chronological age from a medical standpoint. Frailty assessments have been developed as a way to quantify a person's physiological age.

Although frailty indices were initially developed as

ABBREVIATIONS ASD-FI = adult spinal deformity frailty index; ISSG = International Spine Study Group; LOS = length of hospital stay; NF = not frail; PJK = proximal junctional kyphosis; $\mathrm{SF}=$ severely frail; SVA = sagittal vertical axis.

SUBMITTED July 21, 2017. ACCEPTED October 2, 2017.

INCLUDE WHEN CITING DOI: 10.3171/2017.10.FOCUS17472. 
tools to track physiological aging and predict mortality and self-management ability in nonoperatively treated populations, these indices have recently been shown to be better predictors of perioperative adverse events than chronological age alone. ${ }^{6,11,12,17}$ Numerous methods for frailty quantification have been developed and validated. . $, 4,7,13,15-18$ Searle et al. proposed and validated a method for creating frailty indices by using large, existing patient databases. This step-by-step method was used to create a frailty index (the adult spinal deformity frailty index [ASD-FI]) in this study for use with the existing International Spine Study Group (ISSG) ASD prospective patient database.

This method is based on the concept that the number of deficits in health can be used as a surrogate measure for overall frailty. At least 30 deficits in health, covering areas including mobility, activities of daily living, cognitive function, mood, and medical comorbidities, should be selected to accurately calculate a frailty index. Therefore, variables are not weighted in this model. The deficits selected must meet the following criteria: 1) prevalence increases with age (e.g., heart disease), 2) related to health status (e.g., gray hair would be excluded), and 3) prevalence does not saturate too early (e.g., presbyopia would be disqualified because it is nearly universal by age 55 years). The index is expressed as a ratio of the number of health deficits present to the total number of deficits considered. For example, if 40 deficits were considered and 10 were present, the frailty score would be 10:40 or 0.25 . When using this method, the exact variables (deficits in health) included matter less than the number of deficits present. In a series of 1000 iterations, the slope of deficit accumulation ( 0.03 per year) and the submaximal limit at approximately two-thirds of the deficits tested were insensitive to the precise composition of the index. ${ }^{18}$ The frailty index was found to correlate accurately with other objective frailty measures. The key advantage of frailty indices is that they can be created in preexisting patient databases.

Surgery for ASD is known to have high complication rates and therefore warrants thorough preoperative evaluation and risk assessment. Quality and value metrics are increasingly important in the planning of and payment for modern health care delivery and should be based on accurate risk stratification. The development of an index that includes a comprehensive analysis of patient characteristics is important to this risk stratification process. A frailty index quantifies patient physiological reserve comprehensively. This can be used to determine the risk related to operation based only on patient factors and can be used in conjunction with tools examining risk based on surgical invasiveness (e.g., the Adult Spinal Deformity Surgical Invasiveness Index ${ }^{14}$ ) to personalize risk-benefit discussions with patients and preoperatively determine accurate and appropriate quality and value metric ranges. The purpose of this study was to develop and evaluate the ASD-FI by using an existing ASD database. The ASD-FI was examined for correlation with complication incidence, length of hospital stay (LOS), and reoperation rate to determine the value of incorporating this frailty assessment into preoperative risk stratification. We hypothesized that frailty, as measured by the ASD-FI, would be positively correlated with complication rate and LOS.

\section{Methods}

\section{Patient Population}

To develop a frailty index, we used a multicenter, prospective database maintained by the ISSG that consists of US patients with ASD. Institutional review board approval for patient inclusion in this database was obtained by each clinical site that contributed data. Each patient provided written informed consent before inclusion in the database. The database inclusion criteria were as follows: surgery for ASD between 2010 and 2014 for scoliosis (major curve $\geq 20^{\circ}$ ), thoracic kyphosis $\geq 60^{\circ}$, pelvic tilt $\geq 20^{\circ}$, or sagittal vertical axis (SVA) $>5 \mathrm{~cm}$; and age $\geq 18$ years. Whereas some previous frailty studies ${ }^{13,18}$ have excluded all patients $>60$ years old, we chose not to exclude adults on the basis of chronological age because "frailty" can affect surgical outcomes at any age. We included patients with a minimum of 2 years of follow-up.

\section{Development of the ASD-FI}

All variables in the ISSG ASD database were reviewed, and those that met criteria for inclusion in the frailty analysis $(n=40)$, as determined by Searle et al. ${ }^{18}$ were included in the ASD-FI (Table 1). Each variable (i.e., deficit in health) was recorded as a binary variable (e.g., presence vs absence of osteoporosis). The mean score of all deficits was calculated, resulting in a frailty index ranging from 0 to 1 point. Patients with scores of $<0.3$ were considered not frail (NF); those with scores of $0.3-0.5$ were considered frail; and those with scores of $>0.5$ were considered severely frail (SF). These cutoff points were determined on the basis of those used in previous frailty analyses, which were based on risk of mortality curves. ${ }^{13,18}$

\section{Data Analysis}

The primary study outcome was incidence of major complications, which were defined as those that were potentially life-threatening, required reoperation, or caused permanent injury, per Glassman et al. ${ }^{8}$ Major complications were intraoperative vascular, visceral, or neurological injury; postoperative deep infection; pulmonary embolism; junctional failure; and other similar complications. ${ }^{9}$ Secondary outcomes included deep wound infection rate, wound dehiscence incidence, LOS, proximal junctional kyphosis (PJK) incidence, pseudarthrosis incidence, and reoperation rate. This is a retrospective analysis of a prospectively collected database.

\section{Statistical Analysis}

All statistical analyses were performed using Small Stata software, version 14.1 (StataCorp LP). First, univariate linear regression (for continuous variables) and logistic regression (for binary variables) of all independent variables were performed, followed by multivariate analysis of all independent variables found to have a $p$ value $<0.3$. Variables were eliminated until the maximum supportable number of variables was reached. Mul- 
tivariate analyses included surgical invasiveness to assess the independent contribution of frailty to the outcomes of interest.

\section{Results}

In the ISSG ASD database, 450 participants had a minimum 2-year follow-up, 417 of whom had adequate data to calculate the ASD-FI (at least 75\% [n = 30] of all variables using the method of Searle et al. $\left.{ }^{18}\right)$. The mean ASD-FI score was 0.33 (range 0.0-0.8). One hundred seventy-one patients (41\%) were NF, $162(39 \%)$ were frail, and $84(20 \%)$ were SF. There were no significant differences in frailty according to sex or race ( $p>0.05)$. Frailty was associated with age, Charlson Comorbidity Index value, and American Society of Anesthesiologists physical status classification score $(\mathrm{p}<0.05)$. Patients with greater frailty were significantly more likely to have undergone 3 -column osteotomies, to have had a greater number of vertebral levels fused, and to have had decompression, compared with NF patients (Table 2).

\section{Univariate Analysis}

All comparisons are made against the reference group of NF patients. On univariate analysis, frail patients had higher odds of having a major complication (OR 2.9, 95\% CI 1.7-4.9), as did SF patients (OR 3.5, 95\% CI 1.9-6.3) (Table 3). Frail patients had higher odds of experiencing any complication (OR 1.9, 95\% CI 1.2-3.1), as did SF patients (OR 2.1, 95\% CI 1.2-3.7). The odds of having a reoperation were higher for the SF patients (OR 2.0, 95\% CI 1.1-3.7). The SF patients also had higher odds of PJK (OR 2.4, 95\% CI 1.0-6.0), wound dehiscence (OR 11,95\% CI 1.2-94), and deep wound infection (OR 4.3, 95\% CI $1.0-18)$.

Univariate analyses of possible confounding preoperative characteristics and surgical factors were performed, and those with $\mathrm{p}$ values $<0.3$ were included in the multivariate model. These factors included various contributors to surgical invasiveness, such as number of levels fused, performance of osteotomies, operative time, and estimated blood loss. Multivariate models can support inclusion of only a certain number of independent variables, depending on the number of incidences (e.g., the number of major complications in each frailty category). Each multivariate model was reverse-refined to the maximum number of supported independent variables.

\section{Multivariate Analysis}

As with the univariate analysis, all comparisons are made against the reference group of NF patients. On multivariate analysis, the odds of having a major complication were higher for frail patients (OR 2.8, 95\% CI 1.3-5.9) and SF patients (OR 4.1, 95\% CI 1.7-9.6) (Table 4). The odds of having any complication were higher for frail patients (OR 1.8, 95\% CI 1.1-3.0) and SF patients (OR 2.1, 95\% CI 1.1-3.9). The odds of having a reoperation were higher for frail patients (OR 1.7, 95\% CI 1.0-2.9) and SF patients (OR 2.1, 95\% CI 1.1-3.9). The odds of experiencing PJK were higher for frail patients (OR 2.8, 95\% CI 1.2-6.2) and SF patients (OR 3.1,95\% CI 1.2-8.0). The SF patients
TABLE 1. Factors included in the ASD-FI

\begin{tabular}{|c|}
\hline Health deficits \\
\hline Documented by physician \\
\hline$>3$ medical problems \\
\hline Body mass index $<18.5$ or $>30 \mathrm{~kg} / \mathrm{m}^{2}$ \\
\hline Cancer \\
\hline Cardiac disease \\
\hline Currently on disability \\
\hline Depression \\
\hline Diabetes \\
\hline Hypertension \\
\hline Liver disease \\
\hline Lung disease \\
\hline Osteoporosis \\
\hline Peripheral vascular disease \\
\hline $\begin{array}{l}\text { Previous blood clot (deep vein thrombosis/pulmonary embolism/ } \\
\text { stroke) }\end{array}$ \\
\hline Smoking status \\
\hline Patient-reported (questionnaire, question no.) \\
\hline Bladder incontinence \\
\hline Bowel incontinence \\
\hline Deteriorating health this yr (SF-36v2, 2) \\
\hline Difficulty climbing 1 flight of stairs (SF-36v2, 3e) \\
\hline Difficulty driving a car (LSDI, 3) \\
\hline Difficulty getting dressed (SF-36v2, 3j; LSDI, 1 \& 2) \\
\hline Difficulty getting in/out of bed (LSDI, 6) \\
\hline Difficulty sleeping >6 hrs (ODI, 7) \\
\hline Difficulty walking 100 yards (SF-36v2, 3i) \\
\hline Difficulty w/ light activity (SF-36v2, 3b) \\
\hline $\begin{array}{l}\text { Feeling downhearted/depressed most of the time (SF-36v2, 9f; } \\
\text { SRS-22r, 16) }\end{array}$ \\
\hline Feeling tired most of the time (SF-36v2, 9i) \\
\hline Feeling worn out most of the time (SF-36v2, 9g) \\
\hline General health: fair/poor (SF-36v2, 1) \\
\hline Inability to bathe w/o assistance (SF-36v2, 3j; LSDI, 8) \\
\hline Inability to cheer up often (SF-36v2, 9c; SRS-22r, 7) \\
\hline $\begin{array}{l}\text { Inability to do normal work/schoolwork/housework (ODI, 10; } \\
\text { SRS-22r, } 9 \text { \& 12) }\end{array}$ \\
\hline Inability to lift heavy objects (SF-36v2, 3c; ODI, 3) \\
\hline Inability to travel >1 hr (ODI, 9) \\
\hline Inability to walk w/o assistive device (ODI, 4) \\
\hline Leg weakness \\
\hline Loss of balance \\
\hline Not in excellent health (SF-36v2, 11d) \\
\hline Personal care dependency (ODI, 2) \\
\hline Restricted activity level (SRS-22r, 5) \\
\hline Restricted social life (ODI, 8; SRS-22r, 14 \& 18) \\
\hline
\end{tabular}

LSDI = Lumbar Stiffness Disability Index; ODI = Oswestry Disability Index; SF-36v2 = 36-Item Short-Form Health Survey, version 2; SRS-22r $=$ Scoliosis Research Society-22r questionnaire. 
TABLE 2. Characteristics of patients in the ISSG ASD database by frailty status

\begin{tabular}{|c|c|c|c|c|c|c|c|}
\hline \multirow[b]{2}{*}{ Characteristic } & \multicolumn{2}{|c|}{$N F, n=171$} & \multicolumn{2}{|c|}{ Frail, $n=162$} & \multicolumn{2}{|c|}{$S F, n=84$} & \multirow[b]{2}{*}{$\mathrm{p}$ Value } \\
\hline & Mean (SD) & No. (\%) & Mean (SD) & No. (\%) & Mean (SD) & No. $(\%)$ & \\
\hline Age at surgery, yrs & $49(1.3)$ & & $61(1.0)$ & & $63(1.1)$ & & $<0.001^{*}$ \\
\hline Female sex & & $143(84)$ & & $122(76)$ & & $70(83)$ & $0.15 \dagger$ \\
\hline Caucasian & & $139(81)$ & & $146(89)$ & & $93(75)$ & $0.39 \dagger$ \\
\hline ASA PSC score & & & & & & & $<0.001^{*}$ \\
\hline 1 & & $31(20)$ & & $3(1.9)$ & & $1(1.2)$ & \\
\hline 2 & & $99(62)$ & & $79(50)$ & & $23(28)$ & \\
\hline 3 & & $28(18)$ & & $73(46)$ & & $56(68)$ & \\
\hline 4 & & $1(0.6)$ & & $3(1.9)$ & & $2(2.4)$ & \\
\hline Missing & & $12(7.0)$ & & $4(2.5)$ & & $2(2.4)$ & \\
\hline $\mathrm{CCl}$ score & & & & & & & $<0.001^{*}$ \\
\hline 0 & & $96(56)$ & & $35(22)$ & & $3(3.6)$ & \\
\hline 1 & & $36(21)$ & & $40(25)$ & & $16(19)$ & \\
\hline 2 & & $25(15)$ & & $47(29)$ & & $14(17)$ & \\
\hline 3 & & $11(6.4)$ & & $21(13)$ & & $15(18)$ & \\
\hline 4 & & $2(1.2)$ & & $13(8.0)$ & & $13(16)$ & \\
\hline 5 & & $0(0)$ & & $2(1.2)$ & & $12(14)$ & \\
\hline 6 & & $1(0.6)$ & & $4(2.5)$ & & $5(6.0)$ & \\
\hline 7 & & $0(0)$ & & $0(0)$ & & $5(6.0)$ & \\
\hline 8 & & $0(0)$ & & $0(0)$ & & $1(1.2)$ & \\
\hline Op time, hrs & $6.0(2.3)$ & & $6.8(2.0)$ & & $6.9(2.2)$ & & $<0.001^{*}$ \\
\hline EBL, L & $1.4(1.2)$ & & $1.9(1.9)$ & & $2.1(1.8)$ & & $0.03^{*}$ \\
\hline LOS, days & $6.8(2.9)$ & & $8.0(3.9)$ & & $10.5(9.0)$ & & $<0.001^{*}$ \\
\hline \multicolumn{8}{|l|}{ Procedure } \\
\hline Interbody fusion & & $90(53)$ & & $109(67)$ & & $59(70)$ & $0.01 \dagger$ \\
\hline Decompression & & $76(44)$ & & $110(68)$ & & $66(79)$ & $<0.001 \dagger$ \\
\hline 3-column osteotomy & & $19(11)$ & & $40(35)$ & & $27(44)$ & $0.001 \dagger$ \\
\hline No. of instrumented vertebrae & $11(4.3)$ & & $12(4.2)$ & & $12(4.2)$ & & $0.031^{*}$ \\
\hline$\leq 4$ & & $16(9.5)$ & & $9(5.7)$ & & $6(7.1)$ & \\
\hline $5-8$ & & $29(17)$ & & $22(14)$ & & $6(7.1)$ & \\
\hline $9-12$ & & $69(41)$ & & $69(43)$ & & $43(51)$ & \\
\hline $13-16$ & & $36(21)$ & & $31(20)$ & & $18(21)$ & \\
\hline$\geq 17$ & & $18(11)$ & & $28(18)$ & & $11(13)$ & \\
\hline Major complication & & $29(17)$ & & $63(38)$ & & $44(40)$ & $<0.001 \dagger$ \\
\hline
\end{tabular}

ASA = American Society of Anesthesiologists; $\mathrm{CCl}=$ Charlson Comorbidity Index; EBL = estimated blood loss; PSC = physical status classification.

Boldface type indicates statistical significance.

* Statistical analysis performed using Kruskal-Wallis $\mathrm{H}$-test.

$\dagger$ Statistical analysis performed using Pearson chi-square test.

also had higher odds than NF patients of experiencing pseudarthrosis (OR 13, 95\% CI 1.4-121), wound dehiscence (OR 13.4, 95\% CI 1.5-120), and deep wound infection (OR 8.0, 95\% CI 1.3-49).

\section{Discussion}

We found that frailty is independently associated with higher overall complication, major complication, and reoperation rates. Additionally, increasing frailty was associated with increased incidence of PJK, pseudarthrosis, wound dehiscence, and deep wound infection after ASD surgery. This association persisted in multivariate analyses, emphasizing that the contribution of frailty is independent of the contributions of other factors, like surgical invasiveness. In the modern health care system, complication prediction or preoperative risk stratification is becoming increasingly important for reimbursement based on quality and value metrics. Further refinement of preoperative risk stratification can help develop accurate quality and value metrics. Appropriate quality and value metric ranges should not be computed based simply on a broadly applied admission diagnosis-related group, but instead should be appropriately defined using measures of patient physiological risk and procedural complexity. Currently, comorbidities and other baseline patient char- 
TABLE 3. Univariate analysis of outcomes of patients in the ISSG ASD database

\begin{tabular}{|c|c|c|c|c|c|c|}
\hline \multirow[b]{2}{*}{ Outcome } & \multicolumn{3}{|c|}{ Frail vs NF } & \multicolumn{3}{|c|}{ SF vs NF } \\
\hline & OR & $95 \% \mathrm{Cl}$ & $p$ Value & OR & $95 \% \mathrm{Cl}$ & $p$ Value \\
\hline \multicolumn{7}{|l|}{ Complication type* } \\
\hline $\begin{array}{l}\text { Deep wound } \\
\text { infection }\end{array}$ & 2.9 & $0.8-11$ & 0.12 & 4.3 & $1.0-18$ & 0.04 \\
\hline Major & 2.9 & $1.7-4.9$ & $<0.001$ & 3.5 & $1.9-6.3$ & $<0.001$ \\
\hline PJK & 2.4 & $1.1-5.3$ & 0.03 & 2.4 & $1.0-6.0$ & 0.05 \\
\hline Pseudarthrosis & 1.3 & $0.4-5.0$ & 0.68 & 3.2 & $0.9-12$ & 0.08 \\
\hline $\begin{array}{l}\text { Wound dehis- } \\
\text { cence }\end{array}$ & 5.4 & $0.6-47$ & 0.13 & 11 & $1.2-94$ & 0.03 \\
\hline $\begin{array}{l}\text { Total complica- } \\
\text { tions }\end{array}$ & 1.9 & $1.2-3.1$ & 0.005 & 2.1 & $1.2-3.7$ & 0.01 \\
\hline Reoperation* & 1.6 & $1.0-2.8$ & 0.07 & 2.0 & $1.1-3.7$ & 0.02 \\
\hline LOS† & 1.2 & $1.1-1.3$ & $<0.001$ & 1.5 & $1.4-1.7$ & $<0.001$ \\
\hline
\end{tabular}

Boldface type indicates statistical significance.

* Statistical analysis performed using univariate logistic regression.

† Statistical analysis performed using univariate Poisson regression.

acteristics are not directly included in predictions of LOS and complication rates. This is compounded by the fact that the population is aging, and surgeons are operating on patients who are frailer and have more complications (unpublished data).

Surgeries for ASD are known to have high rates of complications. In the Nationwide Inpatient Sample, the overall complication rate was $49 \%, 5$ whereas in a surgeon-maintained database it was $69 \%(\mathrm{n}=448) .{ }^{19}$ In the surgeon-maintained database, rates were as follows: major complications, $39 \%$; radiographic complications, $21 \%$; neurological complications, 20\%; implant-related complications, $16 \%$; and infections, $5.4 \%$. In another study of that same database, the rate of medical complications was $27 \% .^{20}$ Frailty assessments may assist in accurate prediction of risk after spinal surgery and could be invaluable for clinical management and risk stratification.

Many methods of calculating frailty have been proposed and validated. The 3 broad categories of frailty measures are rule-based definitions, summing of impairments, and operational classifications. The frailty index we used in our study, which is an example of summing of impairments, was developed according to the concept that patients who accumulate physiological deficits faster are more frail..$^{13}$ Because no specific parameters, like walking speed, need to be measured, we were able to use data that were collected previously. Given the nature of the prospective, multicenter database of patients with ASD used in our study, the frailty index, as proposed by Searle et al. ${ }^{18}$ was selected as the most appropriate model. However, because frailty assessments have been shown to correlate well, the scores from any frailty assessment would probably have similar predictive power for adverse outcomes and could be used for preoperative risk assessment.

Of note, patients with greater frailty had more severe deformity and underwent more complex surgical procedures. It is impossible to determine from this study wheth-
TABLE 4. Multivariate analysis of outcomes of patients in the ISSG ASD database

\begin{tabular}{|c|c|c|c|}
\hline Outcomes & OR & $95 \% \mathrm{Cl}$ & $p$ Value \\
\hline Deep wound infection* & & & 0.906 \\
\hline 3-column osteotomy & 0.4 & $0.1-1.7$ & 0.20 \\
\hline Frail vs NF & 2.4 & $0.4-15$ & 0.33 \\
\hline Gait imbalance & 3.8 & $0.4-39$ & 0.26 \\
\hline No. of levels fused $†$ & 1.2 & $1.0-1.5$ & 0.05 \\
\hline Op time $\neq$ & 1.7 & $1.2-2.5$ & 0.01 \\
\hline SF vs NF & 8.0 & $1.3-49$ & 0.03 \\
\hline \multicolumn{4}{|l|}{ LOS§ } \\
\hline Allograft used & $1.1 \rrbracket$ & $1.1-1.2$ & 0.001 \\
\hline Decompression & $1.0 \rrbracket$ & $0.9-1.0$ & 0.18 \\
\hline Frail vs NF & $1.2 \pi$ & $1.1-1.3$ & $<0.001$ \\
\hline No myelopathic symptoms & $1.0 \rrbracket$ & $0.9-1.1$ & 0.96 \\
\hline SF vs NF & $1.6 \Phi$ & $1.4-1.8$ & $<0.001$ \\
\hline \multicolumn{4}{|l|}{ Major complications* } \\
\hline 3-column osteotomy & 1.2 & $0.6-2.4$ & 0.62 \\
\hline BMP used & 0.9 & $0.4-1.7$ & 0.66 \\
\hline Caucasian vs other race & 2.2 & $0.7-7.1$ & 0.17 \\
\hline EBLף & 1.8 & $1.4-2.2$ & $<0.001$ \\
\hline Frail vs NF & 2.8 & $1.3-5.9$ & 0.006 \\
\hline No. of levels fused $†$ & 1.0 & $0.9-1.1$ & 0.85 \\
\hline SF vs NF & 4.1 & $1.7-9.6$ & 0.001 \\
\hline Smoker & 0.6 & $0.2-2.2$ & 0.48 \\
\hline \multicolumn{4}{|l|}{ PJK* } \\
\hline Allograft used & 1.5 & $0.7-3.1$ & 0.33 \\
\hline Frail vs NF & 2.8 & $1.2-6.2$ & 0.01 \\
\hline No myelopathic symptoms & 1.2 & $0.5-2.6$ & 0.71 \\
\hline Osteotomy & 0.5 & $0.3-1.1$ & 0.08 \\
\hline SF vs NF & 3.1 & $1.2-8.0$ & 0.02 \\
\hline \multicolumn{4}{|l|}{ Pseudarthrosis incidence* } \\
\hline 3-column osteotomy & 3.2 & $0.8-13$ & 0.11 \\
\hline Decompression & 0.3 & $0.1-1.1$ & 0.06 \\
\hline $\mathrm{EBL}^{* *}$ & 0.9 & $0.6-1.4$ & 0.73 \\
\hline Frail vs NF & 2.7 & $0.3-27$ & 0.40 \\
\hline SF vs NF & 13.0 & $1.4-121$ & 0.03 \\
\hline Reoperation* & & & 0.369 \\
\hline Allograft used & 1.0 & $0.6-1.7$ & 0.91 \\
\hline BMP used & 0.8 & $0.5-1.2$ & 0.26 \\
\hline Female sex & 1.0 & $0.6-1.8$ & 1.00 \\
\hline Frail vs NF & 1.7 & $1.0-2.9$ & 0.05 \\
\hline SF vs NF & 2.1 & $1.1-3.9$ & 0.02 \\
\hline \multicolumn{4}{|l|}{ Total complications* } \\
\hline Caucasian vs other race & 0.6 & $0.3-1.5$ & 0.29 \\
\hline Female sex & 2.1 & $1.2-3.7$ & 0.01 \\
\hline Frail vs NF & 1.8 & $1.1-3.0$ & 0.02 \\
\hline No myelopathic symptoms & 0.8 & $0.4-1.4$ & 0.39 \\
\hline SF vs NF & 2.1 & $1.1-3.9$ & 0.03 \\
\hline Smoker & 0.8 & $0.3-1.6$ & 0.39 \\
\hline
\end{tabular}


» CONTINUED FROM PAGE 5

TABLE 4. Multivariate analysis of outcomes of patients in the ISSG ASD database

\begin{tabular}{crcc}
\hline Outcomes & OR & $95 \% \mathrm{Cl}$ & p Value \\
\hline Wound dehiscence* $^{*}$ & & & \\
\hline Allograft used & 1.9 & $0.5-8.0$ & 0.36 \\
\hline BMP used & 0.3 & $0.1-1.2$ & 0.10 \\
\hline Frail vs NF & 6.1 & $0.7-53$ & 0.10 \\
\hline SF vs NF & 13.4 & $1.5-120$ & $\mathbf{0 . 0 2}$ \\
\hline
\end{tabular}

$\mathrm{BMP}=$ bone morphogenetic protein.

Boldface type indicates statistical significance.

* Statistical analysis performed using multivariate logistic regression.

$\dagger$ For each additional level fused.

$\ddagger$ For each additional hour of operative time.

$\S$ Statistical analysis performed using multivariate Poisson regression.

I Expressed as correlation coefficient.

** For each additional liter of blood lost.

er frailty, which is often associated with low bone density, muscle atrophy, and deconditioning, leads to greater deformity or whether greater deformity, with its associated difficulty with balance and daily activities, leads to greater frailty. Patients who undergo more complex surgical procedures are also known to have higher complication rates. On multivariate analysis, however, frail patients had greater risk of major complications even when controlling for complexity of the procedure, suggesting that frailty is an independent risk factor. Further research on this topic would be beneficial.

A recent study using the modified frailty index developed by the Canadian Study of Health and Aging to analyze patients who had undergone spine surgery and who were entered in the American College of Surgeons National Surgical Quality Improvement Program database showed a strong association between frailty score and complication incidence. ${ }^{1}$ Although this study had a large patient population, the use of large national databases has several recognized limitations. First, the use of current procedural terminology ${ }^{2}$ codes to identify patients can lead to inclusion discrepancies and does not allow stratification by surgical invasiveness. Second, complication incidence was analyzed for only 30 days after surgery. Third, large national databases have been shown to underestimate complication rates. ${ }^{10}$ Fourth, the modified frailty index has not been shown to be an accurate measurement of frailty, because it includes fewer than the validated number of variables.

Our study was designed to address these limitations in a complementary analysis by monitoring a specific patient population for 2 years after surgery and using a more in-depth and disease-specific frailty analysis, which was performed with a validated frailty assessment tool. Our study creates a stronger argument for the incorporation of the frailty index into preoperative risk stratification. Whereas the National Surgical Quality Improvement Program study was limited by a short follow-up period, a less standardized patient population, lack of data on surgical invasiveness, and a modified frailty index, our study had 2 years of follow-up, used surgeon-maintained data from a patient population in whom diagnosis and extent of deformity were known, had surgical invasiveness data that could be used to control for procedure differences when analyzing complication rates, and used a comprehensive frailty index developed using a validated method. However, whereas our study was representative of only patients with ASD undergoing spinal fusion procedures and a comprehensive frailty index, their study had a larger patient population (all spine patients) and a concise index.

Clinical applicability of this study could be challenging because the frailty measurement tool requires documentation of 40 variables and is not weighted by variable. However, because most of the responses were patient generated, this could be integrated into a clinical setting by asking patients to complete the survey in advance as their routine review of systems. Current research is underway investigating the prospective use of the frailty index in a clinical setting. This tool was developed using a validated methodology from geriatrics literature to create a validated tool for frailty assessment with a strong correlation to other frailty measures. In future studies, weighting of variables and decreasing the number of variables required while maintaining accuracy of the frailty measurement achieved with this tool could be pursued. Because frailty indices were initially developed in the field of geriatrics, radiographic measurements were not included in prior indices and were excluded from the ASD-FI. However, recent literature suggests that some radiographic parameters, such as the SVA, increase with age and are potentially related to health status ( 2 of the criteria for inclusion in a frailty index). In future research, measurements like the SVA could be incorporated into frailty analyses as additional variables.

\section{Conclusions}

The ASD-FI was developed according to a validated protocol using the ISSG ASD database. In this database, frail and SF patients had significantly greater odds of incurring major complications than NF patients, as well as higher rates of reoperation and wound infection. These results support the use of the ASD-FI as a component of preoperative risk assessment that would allow the surgeon to counsel patients more effectively on their risk of adverse outcomes after surgery. In addition, this would allow the surgeon to tailor the invasiveness of the surgery on the basis of an accurate assessment of risk of complications. In conclusion, frailty is strongly associated with risk of complications after surgery, and frailty assessments would make a valuable addition to current preoperative risk assessments.

\section{References}

1. Ali R, Schwalb JM, Nerenz DR, Antoine HJ, Rubinfeld I: Use of the modified frailty index to predict 30-day morbidity and mortality from spine surgery. J Neurosurg Spine 25:537-541, 2016

2. American Medical Association: Current Procedural Terminology: CPT 2016. Chicago: American Medical Association, 2016

3. Cigolle CT, Ofstedal MB, Tian Z, Blaum CS: Comparing 
models of frailty: the Health and Retirement Study. J Am Geriatr Soc 57:830-839, 2009

4. Clegg A, Young J, Iliffe S, Rikkert MO, Rockwood K: Frailty in elderly people. Lancet 381:752-762, 2013

5. De la Garza-Ramos R, Jain A, Kebaish KM, Bydon A, Passias PG, Sciubba DM: Inpatient morbidity and mortality after adult spinal deformity surgery in teaching versus nonteaching hospitals. J Neurosurg Spine 25:15-20, 2016

6. Farhat JS, Velanovich V, Falvo AJ, Horst HM, Swartz A, Patton JH Jr, et al: Are the frail destined to fail? Frailty index as predictor of surgical morbidity and mortality in the elderly. J Trauma Acute Care Surg 72:1526-1531, 2012

7. Fried LP, Tangen CM, Walston J, Newman AB, Hirsch C, Gottdiener J, et al: Frailty in older adults: evidence for a phenotype. J Gerontol A Biol Sci Med Sci 56:M146-M156, 2001

8. Glassman SD, Alegre G, Carreon L, Dimar JR, Johnson JR: Perioperative complications of lumbar instrumentation and fusion in patients with diabetes mellitus. Spine J 3:496-501, 2003

9. Glassman SD, Hamill CL, Bridwell KH, Schwab FJ, Dimar JR, Lowe TG: The impact of perioperative complications on clinical outcome in adult deformity surgery. Spine (Phila Pa 1976) 32:2764-2770, 2007

10. Jalai CM, Passias PG, Poorman GW, Smith JS, Scheer JK, Sciubba DM, et al: Comparative analysis of intra-operative complications between a multicenter prospective cervical deformity database versus a nationwide sample. Spine J 16 Suppl:S352-S353, 2016 (Abstract)

11. Joseph B, Pandit V, Sadoun M, Zangbar B, Fain MJ, Friese RS, et al: Frailty in surgery. J Trauma Acute Care Surg 76:1151-1156, 2014

12. Kim SW, Han HS, Jung HW, Kim KI, Hwang DW, Kang SB, et al: Multidimensional frailty score for the prediction of postoperative mortality risk. JAMA Surg 149:633-640, 2014

13. Mitnitski AB, Mogilner AJ, Rockwood K: Accumulation of deficits as a proxy measure of aging. Sci World J 1:323-336, 2001

14. Neuman BJ, Ailon T, Scheer JK, Klineberg E, Sciubba DM, Jain A, et al: Development and validation of a novel adult spinal deformity surgical invasiveness score: analysis of 464 patients. Neurosurgery [epub ahead of print], 2017

15. Rockwood K, Andrew M, Mitnitski A: A comparison of two approaches to measuring frailty in elderly people. J Gerontol A Biol Sci Med Sci 62:738-743, 2007

16. Rockwood K, Song X, MacKnight C, Bergman H, Hogan DB, McDowell I, et al: A global clinical measure of fitness and frailty in elderly people. CMAJ 173:489-495, 2005

17. Schuurmans H, Steverink N, Lindenberg S, Frieswijk N, Slaets JP: Old or frail: what tells us more? J Gerontol A Biol Sci Med Sci 59:M962-M965, 2004

18. Searle SD, Mitnitski A, Gahbauer EA, Gill TM, Rockwood $\mathrm{K}$ : A standard procedure for creating a frailty index. BMC Geriatr 8:24, 2008

19. Soroceanu A, Burton DC, Diebo BG, Smith JS, Hostin R, Shaffrey CI, et al: Impact of obesity on complications, infection, and patient-reported outcomes in adult spinal deformity surgery. J Neurosurg Spine 23:1-9, 2015

20. Soroceanu A, Burton DC, Oren JH, Smith JS, Hostin R,
Shaffrey CI, et al: Medical complications after adult spinal deformity surgery: incidence, risk factors, and clinical impact. Spine (Phila Pa 1976) 41:1718-1723, 2016

\section{Disclosures}

Funding for this database is received through DePuy Synthes. Dr. Ames is a consultant for Stryker, Medtronic, and DePuy; is a patent holder with Fish \& Richardson, P.C.; and receives royalties from Stryker and Biomet Spine. Dr. Bess is a consultant for K2M and AlloSource; is a patent holder with K2M; receives clinical or research support for the study described from DePuy Synthes, NuVasive, and K2M; and receives support of a non-study-related clinical or research effort that he oversees from Medtronic, Biomet, and Orthofix. Dr. Daniels is a consultant for Orthofix, Spineart, and Stryker; receives support of a non-study-related clinical or research effort that he oversees from Orthofix; and receives book royalties from Springer. Dr. Lafage has direct stock ownership in Nemaris, Inc.; is a consultant for NuVasive; receives support of a non-study-related clinical or research effort that she oversees from SRS, NASS, K2M, Stryker, NuVasive, grants from DePuy Spine, and grants received through the ISSG Foundation; and has speaking and/or teaching arrangements with DePuy Spine, AO, and Medtronic Sofamor Danek. Dr. Neuman receives clinical or research support for the study described (includes equipment or material) from ISSG Foundation, and receives support of a non-study-related clinical or research effort that he oversees from DePuy Synthes. Dr. Sciubba is a consultant for Medtronic, and has ownership in DePuy Synthes, Stryker, K2M, and NuVasive. Dr. Shaffrey is a consultant for Medtronic, NuVasive, and Zimmer Biomet; has direct stock ownership in NuVasive; is a patent holder with Medtronic, NuVasive, and Zimmer Biomet; and receives support of a non-study-related clinical or research effort that he oversees from DePuy Synthes, Medtronic, and NuVasive. Dr. Smith is a consultant for Zimmer Biomet, NuVasive, K2M, and AlloSource; receives clinical or research support for the study described (includes equipment or material) from DePuy Synthes/ISSG; receives support of a non-studyrelated clinical or research effort that he oversees from DePuy Synthes/ISSG; and receives royalties from Zimmer Biomet and fellowship funding from the NREF and AOSpine.

\section{Author Contributions}

Critically revising the article: Neuman. Reviewed submitted version of manuscript: all authors.

\section{Supplemental Information \\ Previous Presentations}

Portions of this work were presented as podium presentations at the Scoliosis Research Society Annual Meeting in Prague, Czech Republic, September 2016; at the North American Spine Society Annual Meeting in Boston, MA, October 2016; and at the Global Spine Congress in Milan, Italy, May 2017.

\section{Correspondence}

Brian J. Neuman, Department of Orthopaedic Surgery, The Johns Hopkins University, 601 North Caroline St., JHOC 5241, Baltimore, MD 21287. email: bneuman7@jhmi.edu. 